\title{
Comparison of thermodilution measured extravascular lung water with chest radiographic assessment of pulmonary oedema in patients with acute lung injury
}

Lisa M Brown ${ }^{1,2}$, Carolyn S Calfee ${ }^{3,4}$, James P Howard ${ }^{2,5}$, Thelma R Craig ${ }^{6,7}$, Michael A Matthay ${ }^{2,3,8^{*}}$ and Daniel F McAuley ${ }^{6,7}$

\begin{abstract}
Background: Acute lung injury and the acute respiratory distress syndrome (ALI/ARDS) are characterized by pulmonary oedema, measured as extravascular lung water (EVLW). The chest radiograph (CXR) can potentially estimate the quantity of lung oedema while the transpulmonary thermodilution method measures the amount of EVLW. This study was designed to determine whether EVLW as estimated by a CXR score predicts EVLW measured by the thermodilution method and whether changes in EVLW by either approach predict mortality in ALI/ARDS.

Methods: Clinical data were collected within 48 hours of ALI/ARDS diagnosis and daily up to 14 days on 59 patients with ALI/ARDS. Two clinicians scored each CXR for the degree of pulmonary oedema, using a validated method. EVLW indexed to body weight was measured using the single indicator transpulmonary thermodilution technique.

Results: The CXR score had a modest, positive correlation with the EVLWI measurements $(r=0.35, p<0.001)$. There was a $1.6 \mathrm{ml} / \mathrm{kg}$ increase in EVLWI per 10-point increase in the CXR score $(p<0.001,95 \%$ confidence interval 0.92 2.35). The sensitivity of a high CXR score for predicting a high EVLWI was 93\%; similarly the negative predictive value was high at 94\%; the specificity (51\%) and positive predictive value (50\%) were lower. The CXR scores did not predict mortality but the EVLW thermodilution did predict mortality.
\end{abstract}

Conclusion: EVLW measured by CXR was modestly correlated with thermodilution measured EVLW. Unlike CXR findings, transpulmonary thermodilution EVLWI measurements over time predicted mortality in patients with ALI/ARDS.

Keywords: Extravascular lung water, Chest radiograph, Acute lung injury, Acute respiratory distress syndrome

\section{Background}

Acute lung injury and the acute respiratory distress syndrome (ALI/ARDS) are characterized by an increase in pulmonary capillary permeability to protein leading to extravasation of protein-rich oedema fluid, known as extravascular lung water (EVLW), into the alveoli [1,2]. Importantly, the quantity of EVLW measured early in the course of ALI can predict survival [3,4] Therefore, quantitative and accurate measure of EVLW may be a

* Correspondence: michael.matthay@ucsf.edu

${ }^{2}$ Cardiovascular Research Institute, University of California, San Francisco, CA, USA

${ }^{3}$ Department of Medicine, Division of Pulmonary and Critical Care, University

of California, San Francisco, CA, USA

Full list of author information is available at the end of the article valuable tool for assessment of this patient population. Furthermore, successive and reliable estimates of EVLW could be an effective guide to fluid management and diuretic therapy, potentially offering a superior approach to the contemporary clinical strategies used in patients with ALI/ARDS [5-7]. Therefore, methods to accurately quantify the amount of EVLW may be of value to clinicians who treat patients with ALI/ARDS.

The most commonly used method to estimate the amount of EVLW is the chest radiograph [8]. EVLW also may be measured at the bedside using transpulmonary thermodilution methods [9-11]. Thermodilution methods are invasive because they require that the patient have 
both a central venous and a femoral arterial catheter. It is unclear whether these two methods of evaluating EVLW provide similar information to the clinician. If the chest radiograph findings can accurately predict the amount of EVLW, then it may not be necessary to use invasive methods to measure EVLW. However, if not, measuring EVLW may contribute additional useful information in critically ill patients with ALI/ARDS.

Several early studies of critically ill patients with pulmonary oedema reported that serial chest radiographs were not useful for estimating absolute or changes in the EVLW [12]. These studies found a moderate positive correlation between the chest radiograph findings and the quantity of EVLW measured with either the gravimetric or transpulmonary thermodilution methods [12-17]. However, all of these studies were done more than 20 years ago, and since that time both the technology of portable chest radiographs and measurement of EVLW have improved $[18,19]$. Furthermore, using an objective chest radiograph scoring system may improve the ability to measure pulmonary oedema using chest radiograph findings [20]. Prior studies comparing the chest radiograph with EVLW measured using the thermodilution method used double indicator methods to measure the amount of EVLW [12,14-17]. Currently, the most common thermodilution method of measuring EVLW is the single-indicator transpulmonary thermodilution method (PiCCO, Pulsion Medical Systems, Munich, Germany) [9]. This method has been validated by comparison with the "gold standard" gravimetric method in experimental animal studies [21-23]. Several investigators have studied EVLW in critically ill patients [24-31]. There is some evidence that EVLW measured by the single-indicator transpulmonary thermodilution method early in the course of ALI/ARDS, particularly if indexed to predicted body weight, is associated with poor outcome [3,32].

The main purpose of this study was to determine whether a chest radiograph score that has been recently validated [33] could predict EVLW measured using the transpulmonary thermodilution method in patients with ALI/ARDS. We also determined whether changes in EVLW on consecutive ICU days as measured by the chest radiograph and the transpulmonary thermodilution method predict ventilator-free days and mortality in patients with ALI/ARDS.

\section{Methods}

\section{Subjects}

Patients for this study were enrolled in a randomized, clinical trial investigating the effects of simvastatin on EVLW in patients with ALI/ARDS [34]. Patients were eligible for enrollment if they met the American-European Consensus Conference criteria for ALI or ARDS [35]. The exclusion criteria included creatine kinase $(\mathrm{CK})>10$ times upper limit normal range, liver transaminases $>3$ times upper limit normal range, patients with severe renal impairment (calculated creatinine clearance $<30 \mathrm{ml} / \mathrm{min}$ ) not receiving renal replacement therapy, patients with severe liver disease (Child's Pugh score >11), known lactose intolerance, current treatment with any lipid lowering agent including statins, contraindications to enteral drug administration; age $<18$ years; pregnancy; participation in a clinical trial with an investigational medicinal product within 30 days, unlikely to survive beyond 48 hours, and declined consent. Baseline EVLW in the first 44 patients from this cohort have been published elsewhere in a paper describing the relationship between baseline EVLW indexed to predicted body weight and mortality in ALI/ARDS [32]. Mechanically ventilated patients admitted to a 17-bed tertiary referral center intensive care unit (ICU) in Northern Ireland were prospectively screened for ALI/ARDS during a 2-year period. The local institution and ethics committee approved the protocol for the study, and all patients or their surrogate provided informed consent.

\section{Data collection}

Clinical data were collected within 48 hours of diagnosis of ALI/ARDS and once per day for up to 14 consecutive days. The aetiology of ALI/ARDS was recorded, and patients with pneumonia and septic shock requiring vasopressor support were considered to have an infectious etiology. Baseline Acute Physiology and Chronic Health Evaluation Score (APACHE II), Simplified Acute Physiology Score (SAPS II), Sequential Organ Failure Assessment (SOFA), and Lung Injury Score (LIS) were determined for each patient.

The $\mathrm{PaO}_{2} / \mathrm{FiO}_{2}$ ratio was calculated using arterial blood gas samples and ventilator data. Ventilator parameters recorded included tidal volume, respiratory rate, minute ventilation, positive end expiratory pressure, mean airway pressure, peak pressure, plateau pressure, and static respiratory compliance.

\section{Chest radiograph score}

A chest radiograph scoring system was used by a two clinician panel to score each chest radiograph who interpreted the chest radiographs together at the same time. Thus, separate interpretations were not done, so it was not possible to assess interobserver variability by a kappa value. The clinicians were blinded to the EVLWI measurements. First, the quality of the chest radiograph was classified as acceptable, borderline, or not usable. Next, the probability of atelectasis (yes/no) was determined in each of the following four quadrants: right upper (RU), right lower (RL), left upper (LU), left lower (LL). Finally, the degree of alveolar oedema in each of the four quadrants was scored as follows: 1) $0-25 \%, 2$ ) $25-50 \%$, 3) $50-75 \%$, and 4) $75-100 \%$. The middle value of 
each of the alveolar oedema scores was used to categorize each of the chest radiograph quadrants as follows: 1) $12.5 \%, 2) 37.5 \%, 3) 62.5 \%$, and 4) $87.5 \%$. The four alveolar oedema scores (RU, RL, LU, LL) for each chest radiograph were totaled and divided by four to generate an overall chest radiograph score. This scoring system has been recently validated [33]. Chest radiographs were taken daily between 9:00 and 10:00 A.M. using portable equipment (exposure factor $90 \mathrm{kV}$, 1.4 mAs, a digital system).

\section{EVLWI measurement}

EVLW was measured within 48 hours of diagnosis of ALI/ ARDS and once per day between 8:00 and 9:00 A.M. for up to 14 consecutive days using the singleindicator transpulmonary thermodilution technique (PiCCO Pulsion Medical Systems, Munich, Germany). A $15-\mathrm{mL}$ bolus of $0.9 \%$ normal saline at $4^{\circ} \mathrm{C}$ was injected into a central venous catheter. The change in temperature of this bolus was detected at the thermistor tip of the femoral arterial line and a thermodilution curve was generated. The EVLW was determined based on the characteristics of the thermodilution curve [9]. Three bolus injections were used to calculate the mean EVLW. The EVLW measurements were indexed to the patients' predicted body weight (EVLWI). EVLWI was calculated by dividing the total EVLW by the predicted body weight. The predicted body weight (in kilograms) was calculated as 0.91 (height $[\mathrm{cm}]-152.4$ ) +50 for males or +45.5 for females. The clinicians treating the patients had no knowledge of the results of the EVLWI measurements.

\section{Statistical analyses}

The relationship between the chest radiograph score and EVLWI measurements was graphed using scatterplots and the correlation between the two was calculated using Spearman's correlation. Locally weighted scatterplot smoothing (Lowess) was used to analyze the smoothed, nonparametric relationship between CXR score, and EVLWI. Linear regression was used to determine whether the chest radiograph score predicts EVLWI. The model was clustered by patient, in order to account for repeated measures.

We determined the sensitivity, specificity, positive predictive value, and negative predictive value of the chest radiograph scores using the transpulmonary thermodilution EVLWI measurements as the "gold standard." The EVLWI measurements were split into two groups: high EVLWI $(\geq 16 \mathrm{ml} / \mathrm{kg})$ and low EVLWI $(<16 \mathrm{ml} / \mathrm{kg})$ based on prior data demonstrating that EVLWI $\geq 16 \mathrm{ml} / \mathrm{kg}$ predicted mortality with $100 \%$ specificity and $86 \%$ sensitivity [3,32]. The chest radiograph scores were also split into two groups: high score $(>85)$ and low score $(\leq 85)$ based on analysis of our data, in which one third of the scores were $\leq 85$ and the other two thirds were $>85$.

Next, we compared how well the baseline chest radiograph score, EVLWI, and $\mathrm{PaO}_{2} / \mathrm{FiO}_{2}$ predicted mortality (within 30 days of hospital admission) and ventilatorfree days. The $t$ test was used to determine whether the baseline values of these three predictors differed between survivors and nonsurvivors. Univariate logistic regression was used to determine whether these three baseline values predicted ICU mortality. The area under the receiver operating characteristic curve was determined for each of these three predictors and compared. Univariate linear regression was used to determine whether these three baseline values predicted ventilator-free days.

Finally, Cox regression was performed using the chest radiograph score, EVLWI, and $\mathrm{PaO}_{2} / \mathrm{FiO}_{2}$ as timedependent covariates to determine whether the change in each of these three variables predicts time to death. All patients were followed from the day of randomization until hospital discharge or death. A follow-up time to and including 30 days was used for this analysis. A $p$ value $<0.05$ was considered statistically significant. STATA SE version 10.1 (College Station, TX) was used for all statistical analyses, which were reviewed by a biostatistician.

\section{Results}

There were 59 patients included in these analyses and 476 total observations. The baseline characteristics of the cohort are presented in Table 1. No patients were lost to follow-up.

\section{Correlation between chest radiograph score and EVLWI measurements}

The chest radiograph scores were positively, but modestly, correlated with the EVLWI measurements $(\mathrm{r}=$ $0.35, p<0.001$; Figure 1). In an unadjusted linear model, higher values of the chest radiograph score were associated with higher values of EVLWI. Specifically, there was a $1.6 \mathrm{ml} / \mathrm{kg}$ increase in same day EVLWI per 10 -point increase in chest radiograph score $(p<0.001$, 95\% confidence interval (CI) 0.92-2.35).

As we have done in a prior study [33], in order to investigate the potential confounding effect of atelectasis or suboptimal chest radiographs, we performed additional analyses, first excluding all observations with possible atelectasis in any lung quadrant (remaining, $\mathrm{n}=352$ ) and subsequently excluding all observations with poor radiograph quality or possible atelectasis (remaining, $\mathrm{n}=261$ ). In both sensitivity analyses, the correlations between the chest radiograph score and EVLWI measurements were stronger and there was a greater increase in EVLWI per increase in chest radiograph score (Table 2).

The sensitivity of the chest radiograph score (cutoff $>85$ based on prior published studies [3,24]) as a 


\begin{tabular}{|c|c|}
\hline Characteristic & $\mathrm{n}=59$ \\
\hline Age & $54(38-64)$ \\
\hline Male gender & $45(76 \%)$ \\
\hline \multicolumn{2}{|l|}{ Etiology of ALI/ARDS } \\
\hline Trauma & $19(32 \%)$ \\
\hline Pneumonia & $11(19 \%)$ \\
\hline Aspiration & $9(15 \%)$ \\
\hline Sepsis & $9(15 \%)$ \\
\hline Pancreatitis & $2(3 \%)$ \\
\hline Other/Unknown & $9(15 \%)$ \\
\hline Extravascular lung water index (ml/kg) & $11(9-17)$ \\
\hline Chest radiograph score & $87.5(68.75-87.5)$ \\
\hline APACHE II score & $25(19-30)$ \\
\hline SAPS II score & $53(42-63)$ \\
\hline SOFA score & $10(8-12)$ \\
\hline Lung injury score & $2.5(2-3)$ \\
\hline \multicolumn{2}{|l|}{ Respiratory parameters } \\
\hline $\mathrm{PaO}_{2} / \mathrm{FiO}_{2}$ & $170(129-202)$ \\
\hline Mean airway pressure & $13(9-16)$ \\
\hline Peak airway pressure & $22(17-25)$ \\
\hline Plateau pressure & $22(17-24)$ \\
\hline Compliance & $42 \pm 15$ \\
\hline Dead space fraction & $0.58(0.52-0.65)$ \\
\hline Minute ventilation & $9(8-11)$ \\
\hline Tidal volume & $500(427-560)$ \\
\hline Respiratory rate & $18(15-20)$ \\
\hline PEEP & $8(6-10)$ \\
\hline \multicolumn{2}{|l|}{ Cardiovascular parameters } \\
\hline Heart rate & $94 \pm 19$ \\
\hline Systolic blood pressure & $116(104-127)$ \\
\hline Mean arterial pressure & $78(70-84)$ \\
\hline Central venous pressure & $12 \pm 4$ \\
\hline
\end{tabular}

Data are median (interquartile range), number (\%), or mean \pm standard deviation.

diagnostic test for detecting EVLW compared with EVLWI as measured by the thermodilution method was high $(93 \%)$ as was the negative predictive value (94\%). However, the specificity (51\%) and positive predictive values $(50 \%)$ were lower.

\section{Chest radiograph score and EVLWI measurements and outcomes}

Mortality was $31 \%$. The baseline chest radiograph score and EVLWI were both higher in ICU nonsurvivors compared with survivors (Table 3). The baseline $\mathrm{PaO}_{2} / \mathrm{FiO}_{2}$ ratio was not quite statistically significant in nonsurvivors (Table 4). In logistic regression models, the baseline EVLWI and the $\mathrm{PaO}_{2} / \mathrm{FiO}_{2}$ predicted mortality, and there was a trend towards statistical significance for the ability of the baseline chest radiograph score to predict ICU mortality (Table 4). The areas under the receiver operating characteristic curves for each of the three models were similar. The baseline chest radiograph score and the $\mathrm{PaO}_{2} / \mathrm{FiO}_{2}$ ratio predicted ventilator free days (Table 5). The changes in daily thermodilution measured EVLWI measurements and $\mathrm{PaO}_{2} / \mathrm{FiO}_{2}$ ratio, unlike the chest radiograph score, were predictive of time to death (Table 6).

\section{Discussion}

The primary objectives of this study was to test the correlation between pulmonary oedema assessed using the single indicator transpulmonary thermodilution EVLWI measurement and a validated chest radiograph score in patients with ALI/ARDS as well as to test their predictive value for mortality. There was only a moderate positive correlation between the chest radiograph findings and the EVLWI measurement. This correlation was lower, but similar to those of prior studies done more than 20 years ago in which the correlation ranged from $r=0.45-0.83$ [12-15]. As a dichotomous test, a chest radiograph score $>85$ was sensitive in determining whether EVLW is present, but a score $>85$ was not specific for $E V L W \geq 16 \mathrm{ml} / \mathrm{kg}$.

Using the single-indicator transpulmonary thermodilution method to measure EVLWI is attractive for many reasons. First, this method generates a quantitative measure of EVLW, in contrast to the chest radiograph, which must be interpreted qualitatively by clinicians and is susceptible to interobserver disagreement. We tried to reduce interobserver variability by using an objective validated chest radiograph scoring system [33]. Once ALI/ARDS is established, current practice relies on clinicians accurately interpreting successive chest radiographs to determine whether pulmonary oedema is accumulating or resolving. Although chest radiographs are relatively inexpensive, readily available, and noninvasive, quantitative measures are clinically more useful than qualitative measures. For example, specific cutoffs in a quantitative measure such as EVLWI could be used to guide patient management in a fluid management protocol. Second, the chest radiograph is insensitive to small changes in the quantity of EVLW present [36]. In contrast, small changes (10-20\%) in EVLW can be detected using the single indicator method [37]. Detecting small changes in EVLWI may allow for earlier diagnosis of ALI/ARDS and more precise monitoring of responses to therapeutic measures. Finally, lung inflation affects the appearance of the chest radiograph; likewise, atelectasis may be difficult to differentiate from airspace opacities consistent with alveolar oedema [38]. However, these potential 


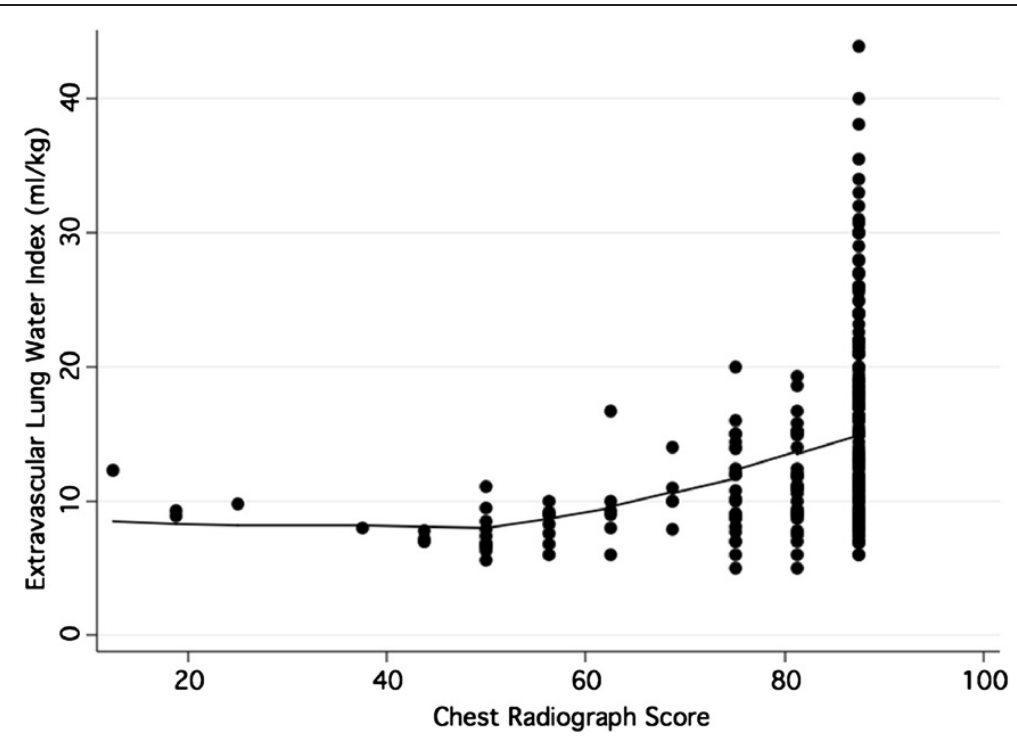

Figure 1 Scatter plot of extravascular lung water index (EVLWI) versus chest radiograph score with a Lowess smoothing line. EVLWI measurements and chest radiograph scores are from all days for which data are available $(n=476)$.

benefits of the transpulmonary thermodilution method must be weighed against the potential complications of this invasive method, including the risk of bleeding at the site of vascular access, arterial injury, and thrombosis.

The change in daily chest radiograph scores was not predictive of time to death. In contrast, EVLWI changes over consecutive ICU days predicted mortality. This builds upon our previous data that baseline EVLWI $>16$ $\mathrm{ml} / \mathrm{kg}$ predicts mortality in ALI [32]. Other studies have reported that EVLW may be an independent predictor of mortality for ICU patients [4]. One study reported a mortality rate of $65 \%$ when EVLW was $>15 \mathrm{ml} / \mathrm{kg}$ [4], and another found that EVLWI $>16 \mathrm{ml} / \mathrm{kg}$ predicted mortality with $100 \%$ specificity and $86 \%$ sensitivity [3]. In addition, EVLWI may have predictive value during the entire clinical course because maximum EVLWI is a predictor of mortality [3,4]. This is consistent with our finding that the change in EVLWI measurements over the ICU course was predictive of mortality. Taken together, these observations indicate that EVLWI measurements may provide a quantitative assessment of lung

Table 2 Correlation between chest radiograph score and EVLWI measurements excluding chest radiographs of borderline quality or with possible atelectasis and of borderline quality

\begin{tabular}{lll}
\hline & $\begin{array}{l}\text { Possible atelectasis } \\
\text { excluded }(\mathbf{n}=\mathbf{3 5 2})\end{array}$ & $\begin{array}{l}\text { Possible atelectasis } \\
\text { and borderline quality } \\
\text { excluded }(\mathbf{n}=\mathbf{2 6 1})\end{array}$ \\
\hline $\begin{array}{lll}\text { Chest radiograph score } \\
\text { correlation with the EVLWI }\end{array}$ & $r=0.41, p<0.001$ & $r=0.48, p<0.001$ \\
Increase in EVLWI $(\mathrm{ml} / \mathrm{kg})^{\mathrm{a}}{ }^{2}$ & $1.8 p<0.001$, & $\begin{array}{l}2.0 p<0.001, \\
95 \% \mathrm{Cl}(0.98-2.64)\end{array}$ \\
& $95 \% \mathrm{Cl}(1.1-2.81)$ \\
\hline
\end{tabular}

${ }^{\text {aPer } 10-p o i n t ~ i n c r e a s e ~ i n ~ c h e s t ~ r a d i o g r a p h ~ s c o r e . ~}$ injury severity, which could be used to guide therapy in ALI/ARDS. Consistent with this, prior studies have reported that EVLWI measurements can be successfully used to monitor response to $\beta$ agonist therapy $[39,40]$. The next step would be to design a clinical trial in which EVLWI measurements are used to guide fluid and diuretic therapy, and within this same trial, determine if decreases in EVLW are associated with a decrease in mortality.

The threshold of $16 \mathrm{ml} / \mathrm{kg}$ for the EVLWI has been used to identify ARDS patients with a higher mortality. This level indicates a high amount of pulmonary oedema, although levels between 10 and $15 \mathrm{ml} / \mathrm{kg}$ represent progressive interstitial and alveolar oedema [41]. Some investigators have concluded that as many as $50 \%$ of patients with a clinical diagnosis of ARDS have a normal EVLWI [42], but more prospective data are needed to assess this issue.

Table 3 Baseline chest radiograph score, EVLWI, and $\mathrm{PaO}_{2} / \mathrm{FiO}_{2}$ in ICU survivors and nonsurvivors

\begin{tabular}{|c|c|c|c|}
\hline Baseline predictor & Mean \pm SD & $95 \% \mathrm{Cl}$ & $p$ value $^{a}$ \\
\hline \multicolumn{4}{|l|}{ Chest radiograph score } \\
\hline Survivors $(n=41)$ & $74 \pm 19$ & $(68-80)$ & 0.007 \\
\hline Nonsurvivors $(n=18)$ & $84 \pm 8$ & (79-88) & \\
\hline \multicolumn{4}{|l|}{ EVLWI } \\
\hline Survivors $(n=41)$ & $12 \pm 5$ & $(11-14)$ & 0.05 \\
\hline Nonsurvivors $(n=18)$ & $17 \pm 9$ & $(12-21)$ & \\
\hline \multicolumn{4}{|l|}{$\mathrm{PaO}_{2} / \mathrm{FiO}_{2}$} \\
\hline Survivors $(n=41)$ & $179 \pm 47$ & $(164-194)$ & 0.08 \\
\hline Nonsurvivors ( $n=18$ ) & $146 \pm 67$ & $(110-181)$ & \\
\hline
\end{tabular}

${ }^{a} p$ value for the difference in baseline predictor between survivors and nonsurvivors, $t$ test with unequal variance. 
Table 4 Univariate logistic regression models for predicting ICU mortality using baseline predictors

\begin{tabular}{lllll}
\hline Predictor $^{\mathbf{a}}$ & $\begin{array}{l}\text { Unadjusted } \\
\text { odds ratio }\end{array}$ & $\boldsymbol{p}$ value & $\mathbf{9 5 \%} \mathrm{Cl}$ & AUROC $^{\mathbf{b}}$ \\
\hline Chest radiograph score & 1.77 & 0.07 & $(0.95-3.3)$ & 0.66 \\
$\begin{array}{l}\text { Extravascular lung } \\
\text { water index (ml/kg) }\end{array}$ & 1.12 & 0.03 & $(1.01-1.24)$ & 0.68 \\
$\mathrm{PaO}_{2} / \mathrm{FiO}_{2}$ & 0.89 & 0.04 & $(0.79-0.99)$ & 0.65
\end{tabular}

aper 10-point increase in chest radiograph score and $\mathrm{PaO}_{2} / \mathrm{FiO}_{2}$.

${ }^{\mathrm{b}}$ Area under the receiver operating characteristic curve.

No statistically significant difference between these three AUROCs, $p=0.9$.

There was a trend towards a lower baseline $\mathrm{PaO}_{2} / \mathrm{FiO}_{2}$ ratio in nonsurvivors, and in logistic regression baseline $\mathrm{PaO}_{2} / \mathrm{FiO}_{2}$ ratio predicted ventilator free days and mortality. In addition, the change in $\mathrm{PaO}_{2} / \mathrm{FiO}_{2}$ ratio over consecutive ICU days predicted time to death. Although not consistent in all studies, baseline $\mathrm{PaO}_{2} / \mathrm{FiO}_{2}$ ratio has been reported in some studies to be lower in nonsurvivors [43-46] and predicts mortality in univariate analyses $[43,44,46]$. In addition, in one large cohort study, $\mathrm{PaO}_{2} / \mathrm{FiO}_{2}$ ratio was an independent predictor of mortality [44]. However, these studies did not test the change in $\mathrm{PaO}_{2} / \mathrm{FiO}_{2}$ ratio over consecutive ICU days as a predictor of mortality. A limitation of $\mathrm{PaO}_{2} / \mathrm{FiO}_{2}$ ratio as a predictor of outcome is the fact that it can be modified independently by adjustment in ventilatory settings, a limitation to which measurement of EVLWI is not susceptible.

The baseline chest radiograph score differed between survivors and non-survivors, but in contrast to EVLWI and $\mathrm{PaO}_{2} / \mathrm{FiO}_{2}$, did not predict mortality. The change in daily chest radiograph scores did not predict time to death although it did predict ventilator-free days. Most prior studies of chest radiograph findings in patients with pulmonary oedema examined the ability of the chest radiograph to predict the amount of EVLW present, not mortality $[12,13,15,17,47]$. Our chest radiograph scoring system is easy to apply clinically, has been validated [33], and has a high sensitivity for the detection of EVLW.

Measurement of the EVLWI using the transpulmonary thermodilution method may serve two important purposes. First, measuring EVLWI using this method may be useful to confirm the presence of an increase in pulmonary

Table 5 Univariate linear regression models for predicting ventilator-free days using baseline predictors

\begin{tabular}{llll}
\hline Predictor $^{\mathbf{a}}$ & $\begin{array}{l}\text { Unadjusted } \boldsymbol{\beta} \\
\text { coefficient }\end{array}$ & $\boldsymbol{p}$ value & $\mathbf{9 5 \%} \mathrm{Cl}$ \\
\hline Chest radiograph score & -1.75 & 0.007 & $(-2.99$ to -0.51$)$ \\
$\begin{array}{l}\text { Extravascular lung water } \\
\text { index }(\mathrm{ml} / \mathrm{kg})\end{array}$ & -0.18 & 0.3 & $(-0.53$ to 0.17$)$ \\
$\mathrm{PaO}_{2} / \mathrm{FiO}_{2}$ & 0.41 & 0.04 & $(0.02-0.81)$ \\
\hline
\end{tabular}

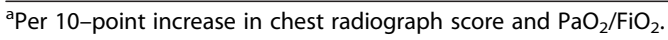

Table 6 Cox regression models for predicting death

\begin{tabular}{llll}
\hline Predictor $^{\mathbf{a}}$ & $\begin{array}{l}\text { Unadjusted } \\
\text { hazard ratio }\end{array}$ & $\boldsymbol{p}$ value & $\mathbf{9 5 \%} \mathrm{Cl}$ \\
\hline Chest radiograph score & 1.72 & 0.3 & $(0.59-4.99)$ \\
$\begin{array}{l}\text { Extravascular lung water } \\
\text { index }(\mathrm{ml} / \mathrm{kg})\end{array}$ & 1.14 & 0.001 & $(1.05-1.23)$ \\
$\mathrm{PaO}_{2} / \mathrm{FiO}_{2}$ & 0.83 & 0.003 & $(0.74-0.94)$ \\
\hline${ }^{\mathrm{a} P e r} 10-$ point increase in chest radiograph score and $\mathrm{PaO}_{2} / \mathrm{FiO}_{2}$. &
\end{tabular}

oedema. In addition, by using the transpulmonary thermodilution method, EVLWI is measured quantitatively. Trending the EVLWI measurements over consecutive ICU days predicts mortality and may be of value for guiding therapy.

Our study has some limitations. First, the total number of deaths (18/59 patients) limited our ability to perform a multivariable regression analysis controlling for potentially confounding conditions that may affect the risk of death. However, because we collected data on multiple days for each patient, we did have sufficient power to detect associations between the chest radiograph score and EVLWI. More importantly, we could use Cox regression models to determine whether the change in each of these predictors (chest radiograph score, EVLWI, and $\mathrm{PaO}_{2} / \mathrm{FiO}_{2}$ ) over time predicted time to death. Second, when scoring the chest radiographs, we only considered the proportion of the airspace that was affected, and not the density of the alveolar oedema. Certain characteristic signs, such as pulmonary congestion and vascular redistribution, are associated with small increases in EVLW [8]. As the quantity of EVLW increases, densities occupy a greater proportion of the total airspace, and as EVLW further increases, the density of the airspace opacities also worsens [8]. If we had accounted for the density in addition to the proportion of airspace affected, the correlation between the chest radiograph score and EVLWI might have been stronger, and chest radiograph score may have been predictive of mortality. Third, many of the chest radiographs were scored at the maximum chest radiograph score. It would have been ideal to have chest radiograph scores distributed more evenly across the entire scoring range to provide more variability to determine how these scores match with the wide range of EVLWI measurements. Fourth, we did not use the PiCCO device to estimate lung vascular permeability, which other investigators have used [48]. Fifth, we did not quantify pleural effusions by ultrasound or CT [49], and sixth, we did not quantify fluid balance in these patients [50].

\section{Conclusions}

EVLW measured by the chest radiograph only modestly predicted EVLWI as measured by the transpulmonary thermodilution technique. However, unlike the chest radiograph score, transpulmonary thermodilution EVLWI 
measurements over consecutive days predicted mortality in patients with ALI/ARDS, as others have reported $[51,52]$. Because it is quantitative and sensitive, and predicts mortality, measurement of EVLWI using singleindicator transpulmonary thermodilution may provide rapidly available and specific information at the bedside in ALI/ARDS. These characteristics suggest that this measurement may be a valuable resource as a prognostic and assessment tool, in both clinical practice and research studies, although prospective studies will be needed to test this hypothesis further.

\section{Competing interests}

None of the authors have a financial relationship with a commercial entity that has an interest in the subject of this manuscript.

\section{Authors' contributions}

$L B, C C, M M$ and DM designed the study. $L B, C C, J H$ and TC contributed to data collection and chest radiograph interpretations. $L B$ and $C C$ analyzed the data. All authors contributed to interpretation of the study results. LB wrote the first draft of the manuscript. All authors reviewed the manuscript and approved the final draft.

\section{Acknowledgment}

The authors appreciate the assistance of Andrew Manies in the preparation of this manuscript.

\section{Funding}

Dr. Brown was supported by NIH T32 GM008258-21. Dr. Calfee was supported by the NIH HL090833 and the Flight Attendant Medical Research Institute. Dr. Howard is a Fellow of the Pediatric Scientist Development Program, and was supported by K12-HD000850 from the Eunice Kennedy Shriver National Institute of Child Health and Human Development, Dr. Matthay was supported by NHLBI HL51856. Dr Craig was supported by the NI Public Health Agency (PHA) Research and Development Division (RDD). Prof McAuley was supported by the NI PHA RDD Translational Research Group for Critical Care.

\section{Author details}

'Department of Surgery, Division of Cardiothoracic Surgery, Washington University, St. Louis, MO, USA. ${ }^{2}$ Cardiovascular Research Institute, University of California, San Francisco, CA, USA. ${ }^{3}$ Department of Medicine, Division of Pulmonary and Critical Care, University of California, San Francisco, CA, USA. ${ }^{4}$ Department of Anesthesia, University of California, San Francisco, CA, USA. ${ }^{5}$ Department of Pediatrics, Division of Critical Care Medicine, University of California, San Francisco, CA, USA. ${ }^{6}$ Regional Intensive Care Unit, Royal Victoria Hospital, Belfast, UK. ${ }^{7}$ Centre for Infection and Immunity, The Queen's University of Belfast, Belfast, UK. ${ }^{8}$ University of California, 505 Parnassus Avenue, Room M-917, San Francisco, CA 94143-0624, USA.

Received: 14 March 2013 Accepted: 29 July 2013

Published: 11 August 2013

\section{References}

1. Ware LB, Matthay MA: The acute respiratory distress syndrome. N Engl J Med 2000, 342:1334-1349.

2. Matthay MA, Ware LB, Zimmerman GA: The acute respiratory distress syndrome. J Clin Invest 2012, 122:2731-2740.

3. Phillips $C R$, Chesnutt MS, Smith SM: Extravascular lung water in sepsis-associated acute respiratory distress syndrome: indexing with predicted body weight improves correlation with severity of illness and survival. Crit Care Med 2008, 36:69-73.

4. Sakka SG, Klein M, Reinhart K, Meier-Hellmann A: Prognostic value of extravascular lung water in critically ill patients. Chest 2002, 122:2080-2086.

5. Eisenberg PR, Hansbrough JR, Anderson D, Schuster DP: A prospective study of lung water measurements during patient management in an intensive care unit. Am Rev Respir Dis 1987, 136:662-668.
6. Mitchell JP, Schuller D, Calandrino FS, Schuster DP: Improved outcome based on fluid management in critically ill patients requiring pulmonary artery catheterization. Am Rev Respir Dis 1992, 145:990-998.

7. Verheij J, van Lingen A, Raijmakers PG, Rijnsburger ER, Veerman DP, Wisselink W, Girbes AR, Groeneveld AB: Effect of fluid loading with saline or colloids on pulmonary permeability, oedema and lung injury score after cardiac and major vascular surgery. Br J Anaesth 2006, 96:21-30.

8. Lange NR, Schuster DP: The measurement of lung water. Crit Care 1999, 3:R19-R24.

9. Brown LM, Liu KD, Matthay MA: Measurement of extravascular lung water using the single indicator method in patients: research and potential clinical value. Am J Physiol Lung Cell Mol Physiol 2009, 297:L547-L558.

10. Lewis FR, Elings VB, Hill SL, Christensen JM: The measurement of extravascular lung water by thermal-green dye indicator dilution. Ann $N$ Y Acad Sci 1982, 384:394-410.

11. Sakka SG, Ruhl CC, Pfeiffer UJ, Beale R, McLuckie A, Reinhart K, Meier-Hellmann A: Assessment of cardiac preload and extravascular lung water by single transpulmonary thermodilution. Intensive Care Med 2000, 26:180-187.

12. Halperin BD, Feeley TW, Mihm FG, Chiles C, Guthaner DF, Blank NE: Evaluation of the portable chest roentgenogram for quantitating extravascular lung water in critically ill adults. Chest 1985, 88:649-652.

13. Snashall PD, Keyes SJ, Morgan BM, MCAnulty RJ, Mitchell-Heggs PF, McLvor JM, Howlett KA: The radiographic detection of acute pulmonary oedema. A comparison of radiographic appearances, densitometry and lung water in dogs. Br J Radiol 1981, 54:277-288.

14. Pistolesi M, Giuntini C: Assessment of extravascular lung water. Radiol Clin North Am 1978, 16:551-574.

15. Laggner A, Kleinberger G, Haller J, Lenz K, Sommer G, Druml W: Bedside estimation of extravascular lung water in critically ill patients: comparison of the chest radiograph and the thermal dye technique. Intensive Care Med 1984, 10:309-313.

16. Baudendistel L, Shields JB, Kaminski DL: Comparison of double indicator thermodilution measurements of extravascular lung water (EVLW) with radiographic estimation of lung water in trauma patients. J Trauma 1982, 22:983-988

17. Sibbald WJ, Warshawski FJ, Short AK, Harris J, Lefcoe MS, Holliday RL: Clinical studies of measuring extravascular lung water by the thermal dye technique in critically ill patients. Chest 1983, 83:725-731.

18. Trotman-Dickenson B: Radiology in the intensive care unit (Part I). J Intensive Care Med 2003, 18:198-210.

19. McAdams HP, Samei E, Dobbins J 3rd, Tourassi GD, Ravin CE: Recent advances in chest radiography. Radiology 2006, 241:663-683.

20. Neyrinck AP, O'Neal H, Lee JW, Curtis B, Matthay MA, Ware L: Quantification of pulmonary oedema on chest radiograph compared with direct measurements of extravascular lung water in humans. Am J Respir Crit Care Med 2009, 179:A3385.

21. Katzenelson R, Perel A, Berkenstadt H, Preisman S, Kogan S, Sternik L, Segal E: Accuracy of transpulmonary thermodilution versus gravimetric measurement of extravascular lung water. Crit Care Med 2004, 32:1550-1554.

22. Kirov MY, Kuzkov W, Kuklin VN, Waerhaug K, Bjertnaes L: Extravascular lung water assessed by transpulmonary single thermodilution and postmortem gravimetry in sheep. Crit Care 2004, 8:R451-R458.

23. Rossi P, Wanecek M, Rudehill A, Konrad D, Weitzberg E, Oldner A: Comparison of a single indicator and gravimetric technique for estimation of extravascular lung water in endotoxemic pigs. Crit Care Med 2006, 34:1437-1443.

24. Berkowitz DM, Danai PA, Eaton S, Moss M, Martin GS: Accurate characterization of extravascular lung water in acute respiratory distress syndrome. Crit Care Med 2008, 36:1803-1809.

25. Mallat J, Pepy F, Lemyze M, Barrailler S, Gasan G, Tronchon L, Thevenin D: Extravascular lung water indexed or not to predicted body weight is a predictor of mortality in septic shock patients. J Crit Care 2012, 27:376-383.

26. Chew MS, Ihrman L, During J, Bergenzaun L, Ersson A, Unden J, Ryden J, Akerman $\mathrm{E}$, Larsson M: Extravascular lung water index improves the diagnostic accuracy of lung injury in patients with shock. Crit Care 2012, 16:R1.

27. Huber W, Mair S, Gotz SQ, Tschirdewahn J, Siegel J, Schmid RM, Saugel B: Extravascular lung water and its association with weight, height, age, and gender: a study in intensive care unit patients. Intensive Care Med 2013, 39:146-150.

28. Wolf S, Riess A, Landscheidt JF, Lumenta CB, Schurer L, Friederich P: How to perform indexing of extravascular lung water: a validation study. Crit Care Med 2013, 41:990-998. 
29. Jozwiak M, Silva S, Persichini R, Anguel N, Osman D, Richard C, Teboul JL, Monnet $X$ : Extravascular lung water is an independent prognostic factor in patients with acute respiratory distress syndrome. Crit Care Med 2013, 41:472-480.

30. Saugel B, Holzapfel K, Stollfuss J, Schuster T, Phillip V, Schultheiss C, Schmid RM, Huber W: Computed tomography to estimate cardiac preload and extravascular lung water. A retrospective analysis in critically ill patients. Scand J Trauma Resusc Emerg Med 2011, 19:31.

31. Saugel B, Ringmaier S, Holzapfel K, Schuster T, Phillip V, Schmid RM, Huber W: Physical examination, central venous pressure, and chest radiography for the prediction of transpulmonary thermodilution-derived hemodynamic parameters in critically ill patients: a prospective trial. J Crit Care 2011, 26:402-410.

32. Craig TR, Duffy MJ, Shyamsundar M, McDowell C, McLaughlin B, Elborn JS, McAuley DF: Extravascular lung water indexed to predicted body weight is a novel predictor of intensive care unit mortality in patients with acute lung injury. Crit Care Med 2010, 38:114-120.

33. Ware LB, Neyrinck A, O'Neal HR, Lee JW, Landeck M, Johnson E, Calfee CS, Matthay MA, the California Transplant Donor N: Comparison of chest radiograph scoring to lung weight as a quantitative index of pulmonary oedema in organ donors. Clin Transplant 2012, 26:665-671.

34. Craig TR, Duffy MJ, Shyamsundar M, McDowell C, O'Kane CM, Elborn JS, McAuley DF: A randomized clinical trial of hydroxymethylglutarylcoenzyme a reductase inhibition for acute lung injury (The HARP Study). Am J Respir Crit Care Med 2011, 183:620-626.

35. Bernard GR, Artigas A, Brigham KL, Carlet J, Falke K, Hudson L, Lamy M, Legall JR, Morris A, Spragg R: The American-European Consensus Conference on ARDS. Definitions, mechanisms, relevant outcomes, and clinical trial coordination. Am J Respir Crit Care Med 1994, 149:818-824.

36. Wheeler AP, Carroll FE, Bernard GR: Radiographic issues in adult respiratory distress syndrome. New Horiz 1993, 1:471-477.

37. Fernandez-Mondejar E, Rivera-Fernandez R, Garcia-Delgado M, Touma A, Machado J, Chavero J: Small increases in extravascular lung water are accurately detected by transpulmonary thermodilution. J Trauma 2005, 59:1420-1423. discussion 1424

38. Trotman-Dickenson B: Radiology in the intensive care unit (part 2). J Intensive Care Med 2003, 18:239-252.

39. Perkins GD, McAuley DF, Thickett DR, Gao F: The beta-agonist lung injury trial (BALTI): a randomized placebo-controlled clinical trial. Am J Respir Crit Care Med 2006, 173:281-287.

40. Licker M, Tschopp JM, Robert J, Frey JG, Diaper J, Ellenberger C: Aerosolized salbutamol accelerates the resolution of pulmonary oedema after lung resection. Chest 2008, 133:845-852.

41. Eichhorn V, Goepfert MS, Eulenburg C, Malbrain ML, Reuter DA: Comparison of values in critically ill patients for global end-diastolic volume and extravascular lung water measured by transcardiopulmonary thermodilution: a meta-analysis of the literature. Med Intensiva 2012, 36:467-474.

42. Michard F, Zarka V, Alaya S: Better characterization of acute lung injury/ ARDS using lung water. Chest 2004, 125:1166. author reply 1167.

43. Estenssoro E, Dubin A, Laffaire E, Canales H, Saenz G, Moseinco M, Pozo M, Gomez A, Baredes N, Jannello G, Osatnik J: Incidence, clinical course, and outcome in 217 patients with acute respiratory distress syndrome. Crit Care Med 2002, 30:2450-2456.

44. Cooke CR, Kahn JM, Caldwell E, Okamoto VN, Heckbert SR, Hudson LD, Rubenfeld GD: Predictors of hospital mortality in a population-based cohort of patients with acute lung injury. Crit Care Med 2008, 36:1412-1420.

45. Cooke CR, Shah CV, Gallop R, Bellamy S, Ancukiewicz M, Eisner MD, Lanken PN, Localio AR, Christie JD: A simple clinical predictive index for objective estimates of mortality in acute lung injury. Crit Care Med 2009, 37(6):1913-1920.

46. Nuckton TJ, Alonso JA, Kallet RH, Daniel BM, Pittet JF, Eisner MD, Matthay MA: Pulmonary dead-space fraction as a risk factor for death in the acute respiratory distress syndrome. N Engl J Med 2002, 346:1281-1286.

47. Sivak ED, Richmond BJ, O'Donavan PB, Borkowski GP: Value of extravascular lung water measurement vs portable chest $\mathrm{x}$-ray in the management of pulmonary oedema. Crit Care Med 1983, 11:498-501.

48. Monnet X, Anguel N, Osman D, Hamzaoui O, Richard C, Teboul JL: Assessing pulmonary permeability by transpulmonary thermodilution allows differentiation of hydrostatic pulmonary oedema from ALI/ARDS. Intensive Care Med 2007, 33:448-453.
49. Deeren DH, Dits H, Daelemans R, Malbrain ML: Effect of pleural fluid on the measurement of extravascular lung water by single transpulmonary thermodilution. Clinical Intensive Care 2004, 15:119-122.

50. Cordemans C, De Laet I, Van Regenmortel N, Schoonheydt K, Dits H, Huber W, Malbrain ML: Fluid management in critically ill patients: the role of extravascular lung water, abdominal hypertension, capillary leak, and fluid balance. Ann Intensive Care 2012, 2(Suppl 1):S1.

51. Cordemans C, De Laet I, Van Regenmortel N, Schoonheydt K, Dits H, Martin G, Huber W, Malbrain ML: Aiming for a negative fluid balance in patients with acute lung injury and increased intra-abdominal pressure: a pilot study looking at the effects of PAL-treatment. Ann Intensive Care 2012, 2(Suppl 1):S15.

52. Martin GS, Moss M, Wheeler AP, Mealer M, Morris JA, Bernard GR: A randomized, controlled trial of furosemide with or without albumin in hypoproteinemic patients with acute lung injury. Crit Care Med 2005, 33:1681-1687.

doi:10.1186/2110-5820-3-25

Cite this article as: Brown et al:: Comparison of thermodilution measured extravascular lung water with chest radiographic assessment of pulmonary oedema in patients with acute lung injury. Annals of Intensive Care 2013 3:25.

\section{Submit your manuscript to a SpringerOpen ${ }^{\odot}$ journal and benefit from:}

- Convenient online submission

- Rigorous peer review

- Immediate publication on acceptance

- Open access: articles freely available online

- High visibility within the field

- Retaining the copyright to your article

Submit your next manuscript at $>$ springeropen.com 